\title{
Invention of the plane geometrical formulae - Part I
}

\author{
Mr. Satish M. Kaple \\ Asst. Teacher Mahatma Phule High School, Kherda Jalgaon (Jamod) - 443402 Dist- Buldana, \\ Maharashtra (India)
}

Abstract: In this paper, I have invented the formulae of the height of the triangle. My findings are based on pythagoras theorem.

\section{Introduction}

A mathematician called Heron invented the formula for finding the area of a triangle, when all the three sides are known. From the three sides of a triangle, I have also invented the two new formulae of the height of the triangle by using pythagoras Theorem. Similarly, I have developed these new formulae for finding the area of a triangle.

When all the three sides are known, only we can find out the area of a triangle by using Heron's formula.By my invention, it became not only possible to find the height of a triangle but also possible for finding the area of a triangle.

I used pythagoras theorem with geometrical figures and algebric equations for the invention of the two new formulae of the height of the triangle. I Proved it by using geometrical formulae \& figures, 50 and more examples, 50 verifications (proofs).

Here myself is giving you the summary of the research of the plane geometrical formulae- Part I

\section{Method}

\section{First taking a scalene triangle $\mathrm{PQR}$}

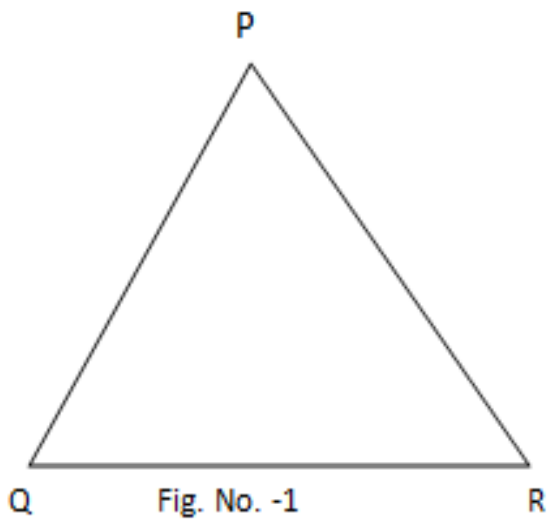

Now taking a, b \& $c$ for the lengths of three sides of $\triangle P Q R$.

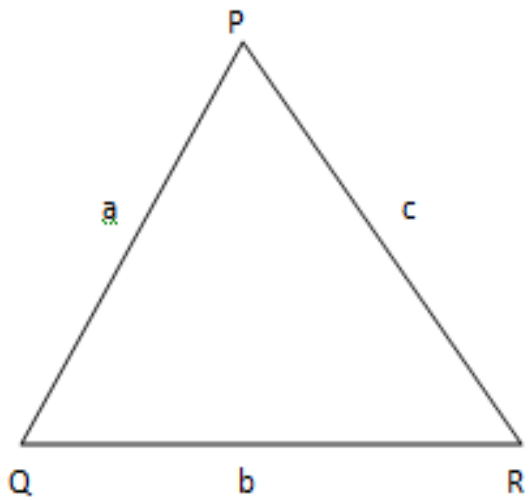

Fig. No. -2 


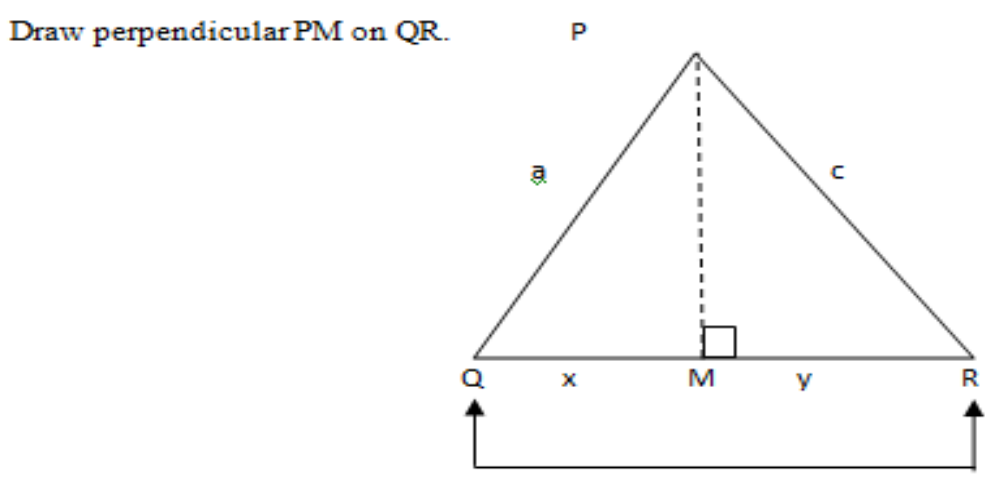

b.

Fig. No. -3

In $\triangle \mathrm{PQR}$ given above,

$\triangle \mathrm{PQR}$ is a scalene triangle and is also an acute angled triangle. $\mathrm{PM}$ is perpendicular to $\mathrm{QR}$. Two another right angled triangles are formed by taking the height PM, on the side QR from the vertex $\mathrm{P}$. These two right angled triangles are $\triangle \mathrm{PMQ}$ and $\triangle \mathrm{PMR}$. Due to the perpendicular drawn on the side $\mathrm{QR}$, Side $\mathrm{QR}$ is divided into two another segment, namely, Seg MQ and Seg MR. QR is the base and PM is the height. and Seg MR.

Here, $a, b$ and $c$ are the lengths of three sides of $\triangle P Q R$. Similarly, $x$ and $y$ are the lengths of Seg MQ

Taking from the above figure,

$\mathrm{PQ}=\mathrm{a}, \mathrm{QR}=\mathrm{b}, \mathrm{PR}=\mathrm{c}$

and height, $\mathrm{PM}=\mathrm{h}$

But $\mathrm{QR}$ is the base, $\mathrm{QR}=\mathrm{b}$

$\mathrm{MQ}=\mathrm{x}$ and $\mathrm{MR}=\mathrm{y}$

$\mathrm{QR}=\mathrm{MQ}+\mathrm{MR}$

Putting the value in above eqn.

Hence, $\mathrm{QR}=\mathrm{x}+\mathrm{y}$

$$
\begin{array}{r}
b=x+y \\
x+y=b---
\end{array}
$$

\section{Step (1) Taking first right angled $\triangle \mathrm{PMQ}$.}

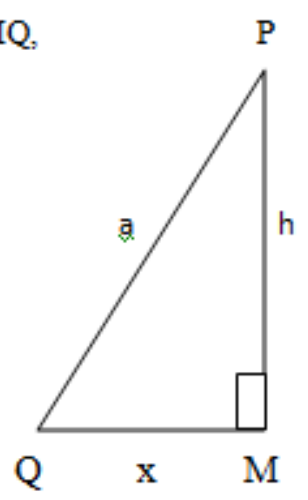

Fig. $\mathrm{No}_{-}-4$

In $\triangle \mathrm{PMQ}$,

Seg PM and Seg MQ are sides forming the right angle. Seg PQ is the hypotenuse and $\angle \mathrm{PMQ}=90^{\circ}$

Let,

$\mathrm{PQ}=\mathrm{a}, \mathrm{MQ}=\mathrm{x}$ and

height, $\mathrm{PM}=\mathrm{h}$

According to Pythagoras theorem,

$(\text { Hypotenuse })^{2}=(\text { One side forming the right angle })^{2}+$

In short,

(Second side forming the right angle) ${ }^{2}$ 


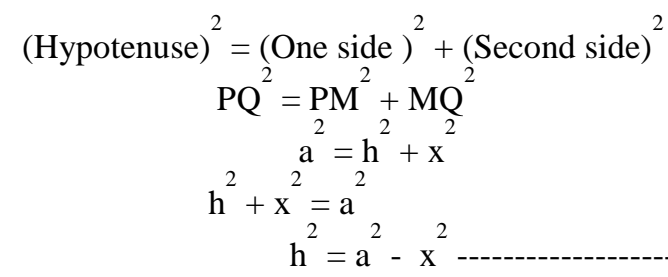

Step (2) Similarly,

Let us now a right angled triangle $\triangle P M R$

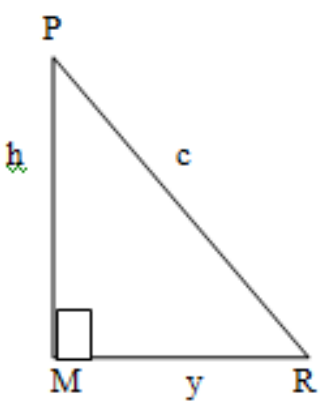

Fig. $\mathrm{No}_{-}-5$

In $\triangle \mathrm{PMR}$,

Seg PM and Seg MR are sides forming the right angle. Seg PR is the hypotenuse.

Let, $\mathrm{PR}=\mathrm{c}, \mathrm{MR}=\mathrm{y}$ and

height, $\mathrm{PM}=\mathrm{h}$ and $\mathrm{m} \angle \mathrm{PMR}=90^{\circ}$

According to Pythagoras theorem,

$(\text { Hypotenuse })^{2}=(\text { One side })^{2}+(\text { Second side })^{2}$

$$
\begin{gathered}
\mathrm{PR}^{2}=\mathrm{PM}^{2}+\mathrm{MR}^{2} \\
\mathrm{c}^{2}=\mathrm{h}^{2}+\mathrm{y}^{2} \\
\mathrm{~h}^{2}+\mathrm{y}^{2}=\mathrm{c}^{2} \\
\mathrm{~h}^{2}=\mathrm{c}^{2}-\mathrm{y}^{2}-
\end{gathered}
$$

From the equations (2) and (3)

$$
\begin{gathered}
a^{2}-x^{2}=c^{2}-y^{2} \\
a^{2}-c^{2}=x^{2}-y^{2} \\
x^{2}-y^{2}=a^{2}-c^{2}
\end{gathered}
$$

By using the formula for factorization, $a^{2}-b^{2}=(a+b)(a-b)$

$$
\begin{aligned}
& (\mathrm{x}+\mathrm{y})(\mathrm{x}-\mathrm{y})=\mathrm{a}^{2}-\mathrm{c}^{2} \\
& \text { But, } \mathrm{x}+\mathrm{y}=\mathrm{b} \text { from eqn. (1) } \\
& \mathrm{b} \times(\mathrm{x}-\mathrm{y})=\mathrm{a}^{2}-\mathrm{c}^{2} \\
& \text { Dividing both sides by } \mathrm{b}, \\
& \frac{\mathrm{b} \times(\mathrm{x}-\mathrm{y})}{\mathrm{b}}=\frac{\mathrm{a}^{2}-\mathrm{c}^{2}}{\mathrm{~b}} \\
& \mathrm{a}^{2}-\mathrm{c}^{2}
\end{aligned}
$$$$
(\mathrm{x}-\mathrm{y})
$$$$
\mathrm{b}
$$

Now, adding the equations (1) and (4)

$$
\begin{gathered}
x+y=b \\
+x-y=\frac{a^{2}-c^{2}}{b} \\
\frac{b x+o=b+\frac{a^{2}-c^{2}}{b}}{2 x=b}+\frac{a^{2}-c^{2}}{b}
\end{gathered}
$$


Solving R.H.S. by using cross multiplication

$$
\begin{aligned}
2 x & =\frac{b}{1}+\frac{a^{2}-c^{2}}{b} \\
2 x & =\frac{b \times b+\left(a^{2}-c^{2}\right) \times 1}{1 \times b} \\
2 x & =\frac{b^{2}+a^{2}-c^{2}}{b} \\
x & =\frac{a^{2}+b^{2}-c^{2}}{b} \times \frac{1}{2} \\
x & =\frac{a^{2}+b^{2}-c^{2}}{2 b}
\end{aligned}
$$

Substituting the value of $\mathrm{x}$ in equation (1)

$$
\begin{aligned}
& \left(\frac{a^{2}+b^{2}-c^{2}}{2 b}\right)+y=b \\
& y=b-\left(\frac{a^{2}+b^{2}-c^{2}}{2 b}\right) \\
& y=\frac{b}{1}-\left(\frac{a^{2}+b^{2}-c^{2}}{2 b}\right)
\end{aligned}
$$

Solving R.H.S. by using cross multiplication.

$$
\begin{aligned}
y & =\frac{b \times 2 b-\left(a^{2}+b^{2}-c^{2}\right) \times 1}{1 \times 2 b} \\
y & =\frac{2 b^{2}-\left(a^{2}+b^{2}-c^{2}\right)}{2 b} \\
y & =\frac{2 b^{2}-a^{2}-b^{2}+c^{2}}{2 b} \\
y & =\frac{-a^{2}+b^{2}+c^{2}}{2 b}
\end{aligned}
$$

The obtained values of $\mathrm{x}$ and $\mathrm{y}$ are as follow.

$$
\begin{aligned}
& \mathrm{x}=\frac{\mathrm{a}^{2}+\mathrm{b}^{2}-\mathrm{c}^{2}}{2 \mathrm{~b}} \\
& \mathrm{y}=\frac{-\mathrm{a}^{2}+\mathrm{b}^{2}+\mathrm{c}^{2}}{2 \mathrm{~b}}
\end{aligned} \text { and }
$$

Substituting the value of $\mathrm{x}$ in equation (2). 


$$
\begin{aligned}
& \mathrm{h}^{2}=\mathrm{a}^{2}-\mathrm{x}^{2} \\
& \mathrm{~h}^{2}=\mathrm{a}^{2}-\left(\frac{\mathrm{a}^{2}+\mathrm{b}^{2}-\mathrm{c}^{2}}{2 \mathrm{~b}}\right)^{2}
\end{aligned}
$$

Taking the square root on both sides,

$\sqrt{h^{2}}=\sqrt{a^{2}-\left(\frac{a^{2}+b^{2}-c^{2}}{2 b}\right)^{2}}$

Height, $h=\sqrt{a^{2}-\left(\frac{a^{2}+b^{2}-c^{2}}{2 b}\right)^{2}}$

Similarly,

Substituting the value of $y$ in equation (3)

$$
\begin{aligned}
& \mathrm{h}^{2}=\mathrm{c}^{2}-\mathrm{y}^{2} \\
& \mathrm{~h}^{2}=\mathrm{c}^{2}-\left(\frac{-\mathrm{a}^{2}+\mathrm{b}^{2}+\mathrm{c}^{2}}{2 \mathrm{~b}}\right)^{2}
\end{aligned}
$$

Taking the square root on both sides:

$$
\begin{aligned}
& \sqrt{h^{2}}=\sqrt{c^{2}-\left(\frac{-a^{2}+b^{2}+c^{2}}{2 b}\right)^{2}} \\
& \sqrt{h^{2}}=\sqrt{c^{2}-\left(\frac{-a^{2}+b^{2}+c^{2}}{2 b}\right)^{2}} \\
& \text { Height } h=\sqrt{c^{2}-\left(\frac{-a^{2}+b^{2}+c^{2}}{2 b}\right)^{2}}
\end{aligned}
$$

These above two new formulae of the height of a triangle are obtained.

By using the above two new formulae of the height of the triangle, new formulae of the area of a triangle are developed. These formulae of the area of a triangle are as follows :-

$\therefore$ Area of $\triangle \mathrm{PQR}=\mathrm{A}(\triangle \mathrm{PQR})$ (A stands for area)

$$
\begin{aligned}
& =\frac{1}{2} \times \text { Base } \times \text { Height } \\
& =\frac{1}{2} \times \mathrm{QR} \times \mathrm{PM}
\end{aligned}
$$


$=\frac{1}{2} \times \mathrm{b} \times \mathrm{h}$

(b for base and $\mathrm{h}$ for height)

$\begin{aligned} & \text { From equation (5), we get } \\ & \therefore \text { Area of } \triangle \mathrm{PQR}=\frac{1}{2}\end{aligned} \times \mathrm{b} \times \mathrm{a}^{2}-\left(\frac{\mathrm{a}^{2}+\mathrm{b}^{2}-\mathrm{c}^{2}}{2 \mathrm{~b}}\right)^{2}$

OR

$\therefore$ Area of $\triangle \mathrm{PQR}=\mathrm{A}(\triangle \mathrm{PQR})$

$=\frac{1}{2} \times$ Base $\times$ Height

$=\frac{1}{2} \times \mathrm{QR} \times \mathrm{PM}$

$=\frac{1}{2} \times \mathrm{b} \times \mathrm{h}$

From equation (6), we get

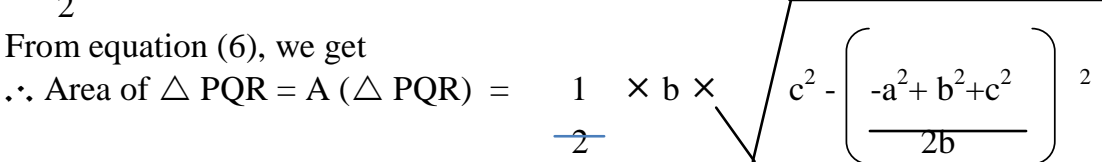

From above formulae, we can find out the area of any type of triangle. Out of two formulae, anyone formula can use to find the area of triangle.

For example:-

Now consider the following examples :-

Ex. (1) If the sides of a triangle are $17 \mathrm{~m} .25 \mathrm{~m}$ and $26 \mathrm{~m}$, find its area.

Here,

$\triangle \mathrm{DEF}$ is a scalene triangle

$l(\mathrm{DE})=\mathrm{a}=17 \mathrm{~m}$

$l(\mathrm{EF})=$ Base, $\mathrm{b}=25 \mathrm{~m}$

$l(\mathrm{DF})=\mathrm{c}=26 \mathrm{~m}$

By using The New Formula No (1)

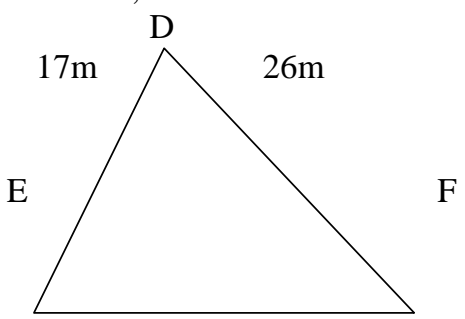

$$
\begin{aligned}
& \text { Height } h=\sqrt{a^{2}-\left(\frac{a^{2}+b^{2}-c^{2}}{2 b}\right]^{2}} \\
& \text { Area of } \triangle \mathrm{DEF}=\mathrm{A}(\triangle \mathrm{DEF}) \\
& =\frac{1}{2} \times \text { Base } \times \text { Height } \\
& =\frac{1}{2} \times \mathrm{b} \times \mathrm{h} \\
& \frac{1}{2} \times b \times \sqrt{a^{2}-\left(\frac{a^{2}+b^{2}-c^{2}}{2 b}\right]^{2}} \\
& =\frac{1}{2} \times 25 \times \sqrt{17^{2}-\left(\frac{17^{2}+25^{2}-(26)^{2}}{2 \times 25}\right]^{2}} \\
& =\frac{25}{2} \times \sqrt{17^{2}-\left[\frac{289+625-676}{50}\right]^{2}} \\
& =\frac{25}{2} \times \sqrt{17^{2}-\left[\frac{238}{50}\right]^{2}}
\end{aligned}
$$


The simplest form of $\frac{238}{50}$ is $\frac{119}{25}$

By using the formula for factorization,

$$
\begin{aligned}
& a^{2}-b^{2}=(a-b)(a+b) \\
& =\frac{25}{2} \times \sqrt{\left(\frac{17-119}{25}\right)\left(17+\frac{119}{25}\right)} \\
& =\frac{25}{2} \times \sqrt{\left(\frac{425-119}{25}\right)\left(\frac{425+119}{25}\right)} \\
& =\frac{25}{2} \times \sqrt{\left(\frac{306}{25}\right) \times\left(\frac{544}{25}\right)} \\
& =\frac{25}{2} \times \sqrt{\frac{306 \times 544}{25 \times 25}} \\
& =\frac{25}{2} \times \sqrt{\frac{166464}{625}}
\end{aligned}
$$$$
\text { The square root of } \frac{166464}{625} \text { is } \frac{408}{25}
$$$$
\begin{aligned}
& =\frac{25}{2} \times \frac{408}{25} \\
& =\frac{408}{2}
\end{aligned}
$$

The simplest form of $\frac{408}{2}$ is 204

$=204 \mathrm{sq} \cdot \mathrm{m}$

$\therefore$ Area of $\triangle \mathrm{DEF}=204 \mathrm{sq} . \mathrm{m}$. 
By using the new formula No (2)

$$
\begin{aligned}
& \text { Height } h=\sqrt{c^{2}-\left(\left(-\frac{a^{2}+b^{2}+c^{2}}{2 b}\right)\right)^{2}} \\
& \text { Area of } \triangle \mathrm{DEF}=\mathrm{A}(\triangle \mathrm{DEF}) \\
& =\frac{1}{2} \times \text { Base } \times \text { Height }=\frac{1}{2} \times \mathrm{b} \times \mathrm{h} \\
& =\frac{1}{2} \times b \times \sqrt{c^{2}-\left(\frac{-a^{2}+b^{2}+c^{2}}{2 b}\right)^{2}} \\
& =\frac{1}{2} \times 25 \times \sqrt{(26)^{2}-\left(\frac{-(17)^{2}+25^{2}+26^{2}}{2 \times 25}\right)^{2}} \\
& =\frac{25}{2} \times \sqrt{(26)^{2}-\left(\frac{-289+625+676}{50}\right)^{2}} \\
& =\frac{25}{2} \times \sqrt{(26)^{2}-\left(\frac{1012}{50}\right)^{2}}
\end{aligned}
$$

The simplest form of $\frac{1012}{25}$ is $\frac{506}{25}$

$=\frac{25}{2} \times \sqrt{(26)^{2}-\left(\frac{506}{25}\right)^{2}}$

By using the formula for factorization,

$$
\begin{aligned}
& a^{2}-b^{2}=(a-b)(a+b) \\
& =\frac{25}{2} \times \sqrt{\left(\frac{26-506}{25}\right) \quad\left(26+\frac{506}{25}\right)} \\
& =\frac{25}{2} \times \sqrt{\left(\frac{650-506}{25}\right)\left(\frac{650+506}{25}\right)} \\
& =\frac{25}{2} \times \sqrt{\left(\frac{144}{25}\right) \times\left(\frac{1156}{25}\right)}
\end{aligned}
$$


$=\frac{25}{2} \times \sqrt{\frac{166464}{625}}$

The square root of $\frac{166464}{625}$ is $\frac{408}{25}$

$=\frac{25}{2} \times \frac{408}{25}$

$=408$

2

The simplest form of 408 is 204

$\overline{2}$

$=204 \mathrm{sq} \cdot \mathrm{m}$

$\therefore$ Area of $\triangle D E F=204$ sq.m.

\section{Verification:-}

Here, $l(\mathrm{DE})=\mathrm{a}=17 \mathrm{~m}$

$$
\begin{aligned}
& l(\mathrm{EF})=\mathrm{b}=25 \mathrm{~m} \\
& l(\mathrm{DF})=\mathrm{c}=26 \mathrm{~m}
\end{aligned}
$$

By using the formula of Heron's

Perimeter of $\triangle \mathrm{DEF}=\mathrm{a}+\mathrm{b}+\mathrm{c}$

$$
\begin{aligned}
& =17+25+26 \\
& =68 \mathrm{~m}
\end{aligned}
$$

Semiperimeter of $\triangle \mathrm{DEF}$,

$$
\begin{aligned}
& S=\frac{a+b+c}{2} \\
& S=\frac{68}{2}=34 \mathrm{~m} .
\end{aligned}
$$

Area of $\triangle \mathrm{DEF}=\mathrm{A}(\triangle \mathrm{DEF})$

$$
\begin{aligned}
& =\sqrt{s(s-a)(s-b)(s-c)} \\
& =\sqrt{\frac{34 \times(34-17)(34-25)(34-26)}{34 \times 17 \times 9 \times 8}} \\
& =\sqrt{2 \times 17 \times 17 \times 9 \times 8} \\
& =\sqrt{(17 \times 17) \times 9 \times(2 \times 8)} \\
& =\sqrt{289 \times 9 \times 16} \times \sqrt{9} \times \sqrt{16} \\
& =\sqrt{289} \times \sqrt{9}
\end{aligned}
$$

The square root of 289 is 17 ,

The square root of 9 is 3 and

The square root of 16 is 4 respectively

$=17 \times 3 \times 4$

$=204$.

$\therefore$ Area of $\triangle \mathrm{DEF}=204 \mathrm{sq} . \mathrm{m}$. 
Ex. (2) In $\triangle \mathrm{ABC}, l(\mathrm{AB})=11 \mathrm{~cm}$, $l(\mathrm{BC})=4 \mathrm{~cm}$ and $l(\mathrm{AC})=7 \mathrm{~cm}$

Find the area of $\triangle A B C$.

$\because \triangle \mathrm{ABC}$ is a scalene triangle

Here,

$$
\begin{aligned}
& l(\mathrm{AB})=\mathrm{a}=11 \mathrm{~cm} \\
& l(\mathrm{BC})=\text { Base }, \mathrm{b}=6 \mathrm{~cm} \\
& l(\mathrm{AC})=\mathrm{c}=7 \mathrm{~cm}
\end{aligned}
$$

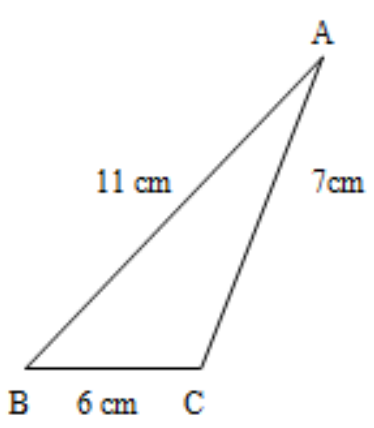

Fig.No.7

By using The New Formula No. (1)

Area of $\triangle \mathrm{ABC}=\mathrm{A}(\triangle \mathrm{ABC})$

$$
\begin{aligned}
& =\frac{1}{2} \times \text { Base } \times \text { Height } \\
& =\frac{1}{2} \times \mathrm{b} \times \mathrm{h}
\end{aligned}
$$$$
=\frac{-1}{2} \times \sqrt{\left(\frac{a^{2}-\left(a^{2}+b^{2}-c^{2}\right.}{2 b}\right)^{2}}
$$$$
=\frac{1}{2} \times 6 \times \sqrt{11^{2}-\left(\frac{11^{1}+6 \cdot(7)^{2}}{2 \times 6}\right)^{2}}
$$$$
=\frac{6}{2} \times \sqrt{121-\left(\frac{121+36-49}{12}\right)^{2}}
$$$$
=3 \times \sqrt{121-\left(\frac{108)^{2}}{12}\right)^{2}}
$$ 
The simplest form of 108 is 9

12

$=3 \times \sqrt{121-(9)^{2}}$

$=3 \times \sqrt{121-81}$

$=3 \times \sqrt{40}$

$=3 \times \sqrt{4 \times 10}$

$=3 \times \sqrt{4} \times \sqrt{10}$

The square root of 4 is 2

$=3 \times 2 \times \sqrt{10}$

$=6 \sqrt{10}$ sq.cm

$\therefore$ Area of $\triangle A B C=6 \sqrt{10}$ sq.cm

By using The New Formula No. (2)

Area of $\triangle \mathrm{ABC}=\mathrm{A}(\triangle \mathrm{ABC})$

$=\frac{1}{2} \times$ Base $\times$ Height

$=\frac{1}{2} \times \mathrm{b} \times \mathrm{h}$

$\frac{1}{2} \times b \times \sqrt{\mathrm{c}^{2}-\left(\left[\frac{-\mathrm{a}^{2}+\mathrm{b}^{2}+\mathrm{c}^{2}}{2 \mathrm{~b}}\right]^{2}\right)}$
$=\frac{1}{2} \times 6 \times \sqrt{7^{2}-\left(\frac{-(11)^{2}+6^{2}+7^{2}}{2 \times 6}\right)^{2}}$

$=\frac{6}{2} \times \sqrt{49-\left(\frac{-121+36+49}{12}\right)^{2}}$

$=3 \times \sqrt{49-\left(\frac{-36}{12}\right)^{2}}$ 
The simplest form of $\frac{-36}{12}$ is $(-3)$

$=3 \times \sqrt{49-(-3)^{2}}$

The square of $(-3)$ is 9

$=3 \times \sqrt{49-9}$

$=3 \times \sqrt{40}$

$=3 \times \sqrt{4 \times 10}=3 \times(\sqrt{4} \times \sqrt{10})$

The square root of 4 is 2 .

$=3 \times 2 \times \sqrt{10}$

$=6 \sqrt{10}$ sq.cm

Area of $\triangle A B C=6 \sqrt{10}$ sq. $\mathrm{cm}$

Verification : -

$\mathrm{EX}(2)$ In $\triangle \mathrm{ABC}, l(\mathrm{AB})=11 \mathrm{~cm}$,

$l(\mathrm{BC})=6 \mathrm{~cm}$ and $l(\mathrm{AC})=7 \mathrm{~cm}$

Find the area of $\triangle \mathrm{ABC}$.

Here, $l(\mathrm{AB})=\mathrm{a}=11 \mathrm{~cm}$

$l(\mathrm{BC})=\mathrm{b}=6 \mathrm{~cm}$

$l(\mathrm{AC})=\mathrm{c}=7 \mathrm{~cm}$

By using the formula of Heron's

Perimeter of $\triangle A B C=a+b+c$

Semiperimeter of $\triangle \mathrm{ABC}$,

$$
\begin{aligned}
S & =\frac{a+b+c}{2} \\
S & =\frac{11+6+7}{2} \\
S & =24=12 \mathrm{~cm} .
\end{aligned}
$$

Area of $\triangle \mathrm{ABC}=\mathrm{A}(\triangle \mathrm{ABC})$

$=\sqrt{s(s-a)(s-b)(s-c)}$
$=\sqrt{12 \times(12-11)(12-6)(12-7)}$ 


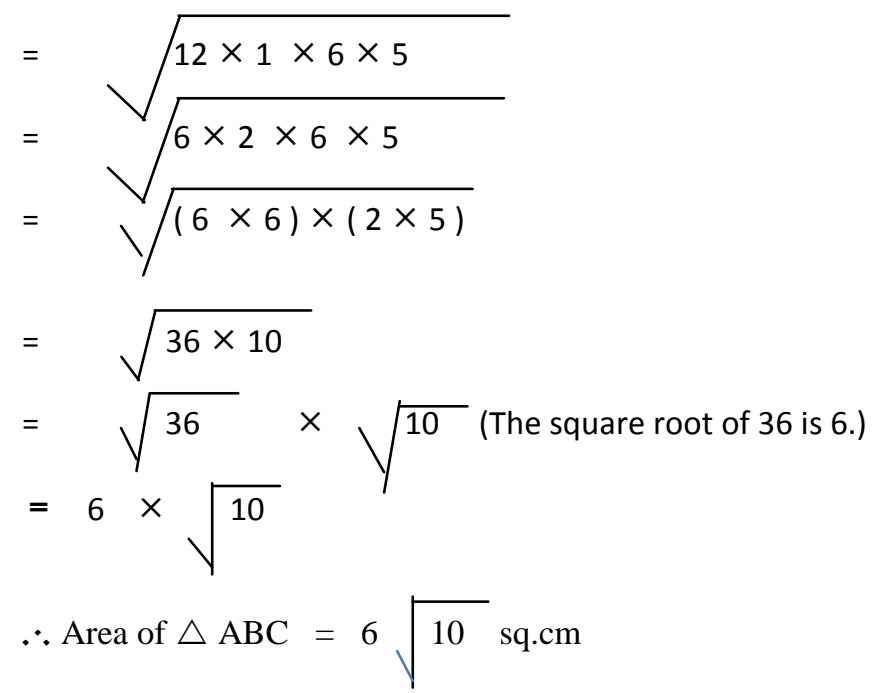

\section{Explanation :-}

We observe the above solved examples and their verifications, it is seen that the values of solved examples and the values of their verifications are equal.

Hence, The New Formulae No. (1) and (2) are proved.

\section{Conclusions :-}

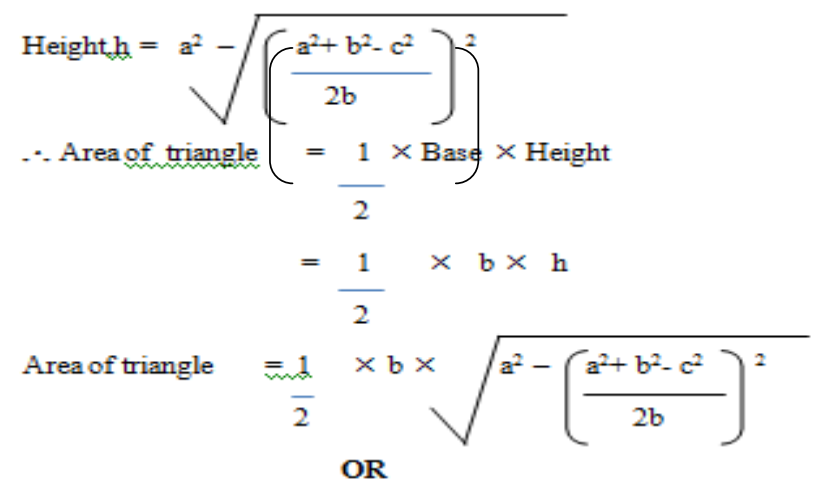

Height $h=\sqrt{c^{2}-\left(\frac{-a^{2}+b^{2}+c^{2}}{2 b}\right)^{2}}$

$\therefore$ Area of triangle $=\frac{1}{2} \times$ Base $\times$ Height

$$
=\frac{1}{2} \times \mathrm{b} \times \mathrm{h}
$$

Area of triangle $=\frac{1}{2} \times b \times \sqrt{c^{2}-\left(\frac{-a^{2}+b^{2}+c^{2}}{2 b}\right)^{2}}$

From above two new formulae, we can find out the height $\&$ area of any types of triangles.

These new formulae are useful in educational curriculum, building and bridge construction and department of land records.

These two new formulae are also useful to find the area of a triangular plots of lands, fields, farms, forests etc. by drawing their maps.

\section{References:-}

[1] Geometry concepts \& pythagoras theorem. 